\title{
Accumulation of Depressive Symptoms and Carotid Intima-Media Thickness : the Cardiovascular Risk in Young Finns Study
}

Keltikangas-Järvinen, Liisa

2017-08

Keltikangas-Järvinen , L , Savelieva , K, Josefsson, K, Elovainio , M , Pulkki-Råback , L , Juonala, M , Raitakari , O T \& Hintsanen, M 2017 , ' Accumulation of Depressive Symptoms and Carotid Intima-Media Thickness : the Cardiovascular Risk in Young Finns Study ' , Annals of Behavioral Medicine , vol. 51 , no. 4 , pp. 620-628 . https://doi.org/10.1007/s12160-017-9884-2

http://hdl.handle.net/10138/233140

https://doi.org/10.1007/s12160-017-9884-2

acceptedVersion

Downloaded from Helda, University of Helsinki institutional repository.

This is an electronic reprint of the original article.

This reprint may differ from the original in pagination and typographic detail.

Please cite the original version. 
This is an Accepted Manuscript of an article published by Springer in Annals of Behavioral Medicine. The final publication is available at link.springer.com via http://dx.doi.org/ $10.1007 / \mathrm{s} 12160-017-9884-2$

Liisa Keltikangas-Järvinen, $\mathrm{PhD}^{1}$, Kateryna Savelieva, $\mathrm{MA}^{1}$, Kim Josefsson, $\mathrm{PhD}^{2}$, Marko Elovainio, PhD $^{1,2}$, Laura Pulkki-Råback, $\mathbf{P h D}^{3,1}$, Markus Juonala, MD, $\mathrm{PhD}^{4}$, Olli T. Raitakari, MD, $\mathrm{PhD}^{5}$, and Mirka Hintsanen, $\mathrm{PhD}^{6,1^{*}}$ (2017). Accumulation of Depressive Symptoms and Carotid Intima-Media Thickness: the Cardiovascular Risk in Young Finns Study. Annals of Behavioral Medicine 51(4), 620-628. doi: 10.1007/s12160017-9884-2

${ }^{1}$ Institute of Behavioural Sciences, University of Helsinki, Helsinki, Finland;

${ }^{2}$ National Institute for Health and Welfare, Helsinki, Finland;

${ }^{3}$ Helsinki Collegium for Advanced Studies, University of Helsinki, Finland;

${ }^{4}$ Department of Medicine, University of Turku, Turku, Finland, Division of Medicine, Turku University Hospital, Turku, Finland, and Murdoch Childrens Research Institute, Parkville, Victoria, Australia;

${ }^{5}$ Research Centre of Applied and Preventive Cardiovascular Medicine, University of Turku, Turku, Finland and Department of Clinical Physiology and Nuclear Medicine, Turku University Hospital, Turku, Finland;

${ }^{6}$ Unit of Psychology, Faculty of Education, University of Oulu, Oulu, Finland

*Correspondence: Mirka Hintsanen, P.O. Box 2000, 90014 University of Oulu, Oulu, Finland. Phone: +358 505695243 and e-mail: mirka.hintsanen@ oulu.fi. 


\section{Accumulation of Depressive Symptoms and Carotid Intima-Media Thickness: the}

\section{Cardiovascular Risk in Young Finns Study}

Background: The association between depressive symptoms and subclinical atherosclerosis has been inconsistent. Purpose: We sought to replicate our previous study, which demonstrated positive relation between depressive symptoms and subclinical atherosclerosis assessed with carotid intima-media thickness (IMT) in men, using newer measurement of carotid IMT and a cumulative loading of depressive symptoms over three follow-ups. Methods: The sample comprised 996 adults (352 men) aged 30 to 45 years in 2007 from a prospective population-based Finnish sample. The participants completed a modified version of Beck Depression Inventory in 1992, 1997, and 2001. Carotid IMT was assessed with ultrasound in 2001 and 2007. Cardiovascular risk factors (i.e., body mass index, systolic blood pressure, low-density lipoprotein cholesterol, and smoking) were measured in childhood (1980) and in adulthood (2007). Results: We found no association between accumulative depression index and carotid IMT before or after controlling for the traditional risk factors (all $p \mathrm{~s} \geq 0.67$ ). Depressive symptoms did not predict IMT progression over two time points and the highest level of carotid wall thickening. Imputed and non-imputed datasets provided similar results. Results remained the same when men and women were analyzed separately. Additional analyses revealed no significant interactions between depressive symptoms and cardiovascular risk factors (i.e., body mass index and systolic blood pressure) on carotid IMT (all $p s>0.15$ ). Conclusions: The findings of this population-based study did not indicate any direct association between depressive symptoms and carotid IMT in asymptomatic, young adults.

Key words: atherosclerosis, carotid intima-media thickness, depression, psychosomatic. 
Since the mid-1980s, depression has been seen to play an important role in a behavioral pathogenesis of coronary heart disease (CHD) (1), even so that in 1999 Hemingway and Marmot named depression one of the four most evident behavioral risk factors of CHD (2). They concluded that in an aetiology and prognosis of CHD, from several behavioral risk factors depression and anxiety, hostility, work stress, and social support have been given the most stable and established roles by previous prospective studies (2). Since then, conflicting findings have increased $(1,3,4)$ questioning at least a general pathogenic role of depression, i.e., a suggestion that depression plays an equal role in clinical and in healthy populations, as well as in different stages of CHD process being correlated both with preclinical stages like atherosclerosis and a progression and development of a diagnosed CHD.

Considerable evidence suggests that depression is highly prevalent in cardiac patients $(5,6)$. One in five patients with CHD is depressed, which is at least 3 times greater than in the general population (6). However, a role of depression in subclinical stages of CHD in asymptomatic, healthy samples is less clear. Findings have been especially inconsistent regarding the thickness of the common carotid artery intima-media complex (IMT), which is widely used as a surrogate marker of carotid atherosclerosis $(7,8)$. Both positive relationships (9-12) and null findings (13-17) have been documented. With few exceptions (18), the general pattern of findings has been that depressive symptoms are positively associated with increased IMT in people over the age of $50(9,10,19-21)$; whereas no association was found for younger participants $(22,23)$ or a combination of younger and older people $(13,14)$. Moreover, the majority of positive findings have exclusively relied on an assessment of depressive symptoms at a single time point. Given that the relationship between depression and carotid IMT is not static (14), examining the chronic or recurrent depression in relation to IMT might help to reduce inconsistencies in the literature. In addition, in those studies, variations of study design, ultrasound protocols, definition of depression, and age of 
participants may account for discrepancies in findings. Therefore, following the same participants in the same frame of reference would be needed to decrease the abovementioned potential sources for inconsistent findings in the existing literature. This study was taken with that purpose.

This study has several aims. First, we examine whether depressive symptoms from several follow-up studies are recurrently associated with carotid IMT in initially healthy and asymptomatic individuals. We have previously found a cross-sectional association between depressive symptoms and carotid IMT but only in men (18). Now we ask whether these results can be repeated in the same participants six years later. If our previous findings maintain, an association should become stronger along with the aging of the sample. Second, we investigate whether a cumulative loading of depressive symptoms from three measurement points (i.e., an accumulative depression index) is linked to carotid IMT. Finally, we explore whether a role of depressive symptoms varies at different risk levels of carotid IMT and in IMT progression over two time points. Those issues were neither examined in our previous study nor taken into account systematically in any previous studies.

\section{Methods}

\section{Study population}

The participants came from the Cardiovascular Risk in Young Finns Study (CRYFS), a population-based follow-up study assessing cardiovascular risks from childhood into adulthood. The original sample $(N=3,596$, collected in 1980) included randomly selected Finnish children and adolescents from six different age cohorts from 3 to 18 years. The design of the study and the sample selection have been described in detail elsewhere (24).

Participants twelve years of age and older gave informed consent, and the parents gave consent for younger participants. The study was approved by local ethics committees and conducted in accordance with the Helsinki declaration. 


\section{Procedure}

The current study comprised the baseline examination in 1980 and follow-up examinations in 1992, 1997, 2001 and 2007. At baseline, clinical measurements of children/adolescent were conducted by trained staff who obtained measures of blood pressure, weight and height, and also drew venous blood samples. In the 1992, 1997, and 2001 followup studies, participants self-reported their depressive symptoms. In the 2001 and 2007 followup studies, participants' (30-45 years old in 2007) carotid IMT and cardiovascular risk factors were assessed (along with other biomedical measures not relevant for the current study). Participants with a diagnosed or self-reported diabetes or self-reported CHD $(n=48)$ were excluded from the sample. Participants were also excluded if they had not answered at least $70 \%$ of the depression items each year. There were 2303, 2079, and 2072 participants who had data for depressive symptoms in 1992, 1997, or 2001, respectively. There were 1302 participants who had data for depressive symptoms in all three measurements and 996 of these had also complete data on carotid IMT and risk factors in 2007, which formed the analytic sample of the current study. Compared with the eligible sample at the baseline of the CRYFS, the participants in the present study were more often female $\left(64.7 \%\right.$ vs. $45.7 \%, \chi^{2}(1)$ $=103.15, p<0.001)$. Differences in other childhood/adolescence baseline characteristics were minimal and statistically nonsignificant (all $p \mathrm{~s}>0.30$ ).

\section{Measures}

Depressive symptoms. Depressive symptoms were assessed using a modified version of the Beck Depression Inventory (mBDI). The original version of the BDI (25) offers 4 alternative statements of 21 items ranging from minimal to severe symptoms of depression (e.g., (0) "I do not feel sad", (1) "I feel sad", (2) "I am sad all the time and I cannot snap out of it", (3) "I am so sad or unhappy that I cannot stand it"). In the present study, the participants were asked to rate the second mildest descriptions of the original 21 items (e.g., 
"I often feel sad") on a five-point scale ranging from totally disagree (1) to totally agree (5).

Originally, these second mildest items were selected because they were suggested to measure depressive symptoms more accurately among the normal population than corresponding clinical scales (26). Previous research supports this assumption (27,28). It has been reported that the modified version of BDI is highly correlated with original BDI-II $(r=.77)(27)$. Scale reliability of the mBDI was 0.89 in 1992, 0.91 in 1997, and 0.92 in 2001 . The mean score of all the 21 items formed the general depression index each year. To capture the accumulative effect of depressive symptoms in the general population, these three depressive indexes were summed together. The accumulative depression index was used as a continuous variable in all main analyses (ranged 3.10-11.46) in order not to lose any information by categorization. The sensitivity analyses were conducted using accumulative depression index as a dichotomous variable (i.e., a multiple depressive symptoms group and a fewer depressive symptoms group). Three cutoff points were applied for accumulative depression index: participants in highest $10 \%$ of the sample distribution, in highest $20 \%$, and using median split.

Carotid IMT. Ultrasound studies in the present study were performed in 2001 and 2007 using Sequoia 512 ultrasound mainframes with 13.0-MHz linear array transducers. The left carotid artery was scanned by ultrasound technicians following a standardized protocol (29). In brief, a magnified image was recorded of the angle showing the greatest distance between the lumen-intima interface and the media-adventitia interface. A moving scan (duration 5 seconds) that included the beginning of the carotid bifurcation and the common carotid artery was recorded and stored in digital format on optical discs for subsequent offline analysis. The digitally stored scans were manually analyzed by a single reader who was blinded to subjects' details. The analyses were performed using ultrasound calipers. From the 5-second clip image, the best quality end-diastolic frame was selected (incident with the Rwave on a continuously recorded electrocardiogram). From this image, at least four 
measurements of the common carotid wall were taken approximately $10 \mathrm{~mm}$ proximal to the bifurcation in order to derive mean carotid IMT. A $6.4 \%$ between-visit coefficient and a 5.2\% between-observer coefficient of variation in the IMT measurements have been reported (29). Six-year change in carotid IMT was calculated as mean carotid IMT from 2007 minus mean carotid IMT from 2001. In agreement with prior research (30), we controlled for baseline carotid IMT (from 2001) in all analyses where the outcome variable was carotid IMT progression. To capture the severe thickening of a carotid wall, carotid IMT was divided into quartiles based on the population distribution (31). High level of carotid wall thickening was defined by assigning a point to the top $25 \%$ of the participants and 0 to all other participants.

Cardiovascular risk factors. The risk variables measured in childhood (in 1980) included low-density lipoprotein (LDL) cholesterol, body mass index (BMI), and systolic blood pressure. The risk factors measured in adulthood (2007) were LDL cholesterol, BMI, systolic blood pressure, and smoking. These risk factors have been previously shown to predict adult common carotid artery IMT in the same data set (29). Smoking status was assessed by a questionnaire, and those smoking on a daily basis were classified as smokers. BMI was calculated as weight in kilograms divided by the square of their height in meters. Height was measured with a wall-stationed statiometer and weight with digital scales. All measurements of lipid levels were performed in duplicate in the same laboratory.

Standardized enzymatic methods were used for measuring levels of serum total cholesterol, triglycerides, and high-density lipoprotein cholesterol. The LDL cholesterol concentration was calculated by the Friedewald formula (32). Blood pressure was measured with a standard mercury sphygmomanometer in 1980 and with a random zero sphygmomanometer in 2007. Details of the methods have been reported elsewhere (29).

\section{Statistical analyses}


Main analyses. Linear regression analyses were used to examine the relationships between accumulative depression index and carotid IMT. Interactions between sex and depressive symptoms, as well as age and depressive symptoms on carotid IMT were analyzed, but both appeared nonsignificant. Thus, these interactions were dropped from further analyses. Two models were constructed: in Model 1, only sex and age were controlled for; in Model 2, sex, age, and the cardiovascular risk factors from childhood and adulthood were adjusted for. All analyses were first performed with carotid IMT in 2007 as the dependent variable and then with IMT progression over 6 years. In addition, logistic regression analyses were used to test the relationship between the accumulative depression index and the severe thickening of a carotid wall. All analyses were also repeated separately for men and women, as well as for older (aged 39-45 years in 2007) and younger (30-36 years old in 2007) age groups. Finally, sensitivity analyses were conducted to examine whether high levels of depressive symptoms (as indicated using three different cutoff points, such as participants in top $10 \%$, top $20 \%$, and based on median split) contributed to the progression of atherosclerosis.

We also examined whether depressive symptoms from the 1992, 1997, 2001, and 2007 follow-ups were associated with carotid IMT from 2007 separately for men and women. Following the same procedure as previously applied (18), several regression models were tested. First, carotid IMT was regressed on age and depressive symptoms from 1992, 1997, 2001, and 2007 in separate models. Second, age and depressive symptoms from 1992, 1997, 2001, and 2007 were entered as independent variables into the model simultaneously. Finally, the cardiovascular risk factors from 1980 and 2007 along with depressive symptoms from four time points were entered into the fully-adjusted regression model. We also repeated the analyses using the dichotomous depression variables from each year. In order to be consistent with our previous findings (18), we classified participants with the mean depression score in 
the highest $10 \%$ into the multiple depression group and others into a fewer depression group in those analyses.

Supplementary analyses. We also conducted additional analyses to test whether the absence of the association between depressive symptoms and IMT may be explained by moderating effect of cardiovascular risk factors, which were associated with higher IMT. Three separate linear regression models were applied first to test the interactions between accumulative depression index and adult BMI, as well as between accumulative depression index and systolic blood pressure from childhood and adulthood on carotid IMT without any adjustments; next adjusted for age and sex; and finally conducted separately for men and women.

Multiple imputation by chained equations was done in STATA 13.1 (33) to estimate missing values for participants with missing data in depressive symptoms and cardiovascular risk factors. We calculated the main statistical analyses using the pooled estimates of 50 imputed data sets $(n=2,160)$.

All statistical analyses were calculated in STATA version 13.1.

\section{Results}

Table 1 shows the characteristics of the study participants. There were statistically significant sex differences in adults' low-density lipoprotein cholesterol, BMI, systolic blood pressure, depressive symptoms, and carotid IMT (all $p \mathrm{~s}<0.001$ ). Women were more depressed on average compared to men (6.42 vs. 5.94, $p<0.001)$. In contrast, the LDL cholesterol, BMI, and systolic blood pressure were significantly higher in men. To continue, men also had higher carotid IMT than women in 2007 (0.63 vs. $0.61, p<0.001)$. The data about IMT progression was available for 915 participants. The bivariate correlation between two measurements of carotid IMT (from 2001 and 2007) was $r=0.61, p<0.001$. The IMT progression variable was normally distributed for both men and women with average scores 
$0.05 \mathrm{~mm}(S D=0.09)$ and $0.04 \mathrm{~mm}(S D=0.08)$, respectively. The measurement error in the IMT assessments was at least of similar size or even larger than the standard deviation of IMT progression. Thus, the IMT progression assessment was diluted by measurement error which makes finding significant associations quite unlikely. Despite this, IMT progression was analyzed to examine all possible associations.

Table 2 presents the bivariate correlations between depressive symptoms and cardiovascular risk factors. In men, only higher BMI in adulthood was related to accumulation of depressive symptoms. In women, both higher BMI and smoking in adulthood were associated with higher depressive symptoms. Neither carotid IMT nor IMT progression was directly related to accumulative depressive symptoms in men or women.

No statistically significant associations were found between the accumulative depression index and either carotid IMT or progression of carotid IMT over six years (Table 3). Correspondingly, the logistic regression analyses revealed no significant associations between accumulative depression index and the higher level of carotid IMT (findings not shown). The association was not significant before or after controlling for various cardiovascular risk factors (BMI, systolic blood pressure, LDL-cholesterol, and smoking in childhood and adulthood). Older age and male sex were robustly associated with higher carotid IMT in all models (all ps < 0.001). Higher childhood systolic blood pressure and increased BMI in adulthood were also related to higher level of carotid IMT (all $p s<0.01$ ). The results were the same when we additionally controlled for adult waist circumference in order to take into account the participants' gaining body fat. The findings also remained intact when accumulative depression index was used in the sensitivity analyses as a dichotomous variable (multiple symptoms depressive group was coded as highest $10 \%, 20 \%$, and $50 \%$ of the sample). All variations of these primary analyses also failed to yield meaningful associations. No significant results were found when the analyses were conducted separately 
for men and women (Supplementary Table 1) or for older and younger age groups

(Supplementary Table 2). Moreover, when the initially excluded participants $(n=48)$ who had a diagnosed or self-reported diabetes or self-reported CHD were included in the sample, no significant differences were observed. Finally, the analyses with the imputed data also failed to provide significant associations between depressive symptoms and carotid IMT, as well as IMT progression (Supplementary Table 3) and the higher level of carotid IMT (data not shown).

We also examined the link between depressive symptoms from 1992, 1997, 2001, and 2007 with carotid IMT separately for men and women. The relation between continuous depressive symptoms scores from these years and carotid IMT were not statistically significant in all models either for men or women. The high level of depressive symptoms (highest 10\%) in 1997 and 2001 were associated with carotid IMT only in men when depressive symptoms from four follow-ups were entered into the model simultaneously (depressive symptoms in 1997: unstandardized $B=-0.07, p=0.016$; depressive symptoms in 2001: unstandardized $B=0.08, p=0.003$ ). The adjustment for additional cardiovascular risk variables did not substantially alter this association (see Supplementary Table 4). The analyses with the imputed data, however, revealed no statistically significant associations between both continuous and dichotomous depressive symptoms scores and carotid IMT in any models either for men or women (Supplementary Table 5).

Finally, no significant interactions between depressive symptoms and cardiovascular risk factors (i.e., BMI and systolic blood pressure) on carotid IMT were found (all $p$ s > 0.15). The findings with the imputed data were similar to those in the complete data.

\section{Discussion}

Findings from this population-based cohort study do not provide an evidence for an association between depressive symptoms and carotid IMT in healthy, asymptomatic 
individuals. Associations were nonsignificant before and after adjusting for traditional CHD risk factors in childhood and adulthood. Neither linear relationships nor the relationships between extremely high levels of accumulative depressive index and carotid IMT were found. Cumulative score of depressive symptoms also failed to explain IMT progression over a follow-up of 6 years. Several variations of the analyses (i.e., separation of men and women, multiple imputation, and covariate removal) were not able to identify a reason for the lack of expected results. This indicates that among healthy people under the age of fifty depressive symptoms may not play any significant role in a pathogenesis of CHD.

Prior population-based studies have investigated the association between depression and atherosclerosis, although evidence is controversial: some studies found the relationship significant $(10,19,34)$, while others did not $(13,16,35)$. Overall, the systematic methodological differences, such as different sample size, prospective or cross-sectional study designs, and the way depression and carotid IMT were measured do not seem to account for the absence or presence of a significant relationship between depression and atherosclerosis. In addition, we were not able to replicate our previous findings (18) in older age cohorts and in other study waves. Thus, we have to include our own positive result to the list of "random findings" as well.

To the best of our knowledge, no previous study has systematically examined all possible variants of an association between depressive symptoms and atherosclerosis, i.e., linear associations, associations in the extremes and in different sex groups, using the IMT progression variable over 6 years, and cumulative score for depressive symptoms over a follow-up period of 9 years. Although no evidence was found in our study, the findings cannot falsify the role of depression in a pathogenesis of CHD. A recent review suggests that depression is a non-causal risk marker for CHD, and that causality cannot be established (36). According to this view, depression co-varies with some mechanisms leading to CHD but is 
not causally related to it. Therefore, it is possible that depression plays a role in the pathogenesis of CHD through other parameters (e.g., behavioral or biological factors) by making depressed patients more vulnerable to other cardiac risks (1). For example, depression is associated with higher rates of harmful lifestyle habits, including unhealthy diet, reduced exercise, and smoking (6). With respect to biological mechanisms, some evidence suggests that depression is linked to inflammatory process (37), altered hypothalamic pituitary adrenal hormones (38), autonomic nervous system dysregulations (39), and platelet dysfunction (40), all of which are implicated in the pathogenesis of CHD. Moreover, time dynamics should be also taken into account. Those individuals who were depressed early in life may be a selected group who would have developed especially unhealthy lifestyles, which in turn would increase their IMT. However, in this case the association between depression and IMT should be attenuated if health behaviors were taken into account. This was not the case in our previous study that found association between depression and IMT in men even though the health behaviors were adjusted for (18). It should be noted that lifestyle may also have a stronger impact with increasing age (41), whereas depression may play less important role (42).

To continue, we should not exclude a role of depression for atherosclerosis in the certain context (i.e., the effect of age). The considerable amount of studies have found an association between depression and atherosclerosis in older populations (50 years of age and older) $(9,10,12,19-21,43)$. Although there was no relation between depressive symptoms and carotid IMT in older participants (aged 39-45 years) in this study, it is possible that atherosclerosis may be detectable relatively late in life. This may be a reason why studies with younger participants (age 24-52) have not found an association (22,23). Finally, different measurements of atherosclerosis may partly account for inconsistent findings in the literature. Although carotid IMT is often considered as a surrogate marker of atherosclerosis, some 
evidence has suggested that carotid IMT reflects an adaptive response of the vessel wall to changes in shear stress, lumen diameter, tensile stress, and pressure instead of an atherosclerotic thickening (44). Some studies have shown that depression is related to plaque $(11,23)$ or coronary artery calcification $(12)$, which are considered as more reliable predictors of the atherosclerotic process than IMT $(23,45)$.

\section{Strengths and Limitations}

Strengths of this study involve its populations-based sample, long follow-up period over 27 years, longitudinal design with several measurements of depressive symptoms and IMT, and the possibility to adjust for childhood cardiovascular risk factors, thereby eliminating the confounding influence of baseline health. The accumulative depression index based on three time points over 10 years ascertained to capture chronic or recurrent depressive symptoms better than a measurement from a single point in time.

In interpreting these results, several limitations should be taken into account. As with most longstanding studies, attrition in this follow-up study was considerable. To deal with the possibility that selective drop-out would have biased our findings, we conducted analyses using multiply imputed data, and the results were similar in most cases to those in the original data. Furthermore, we were not able to define a clinically significant cutoff point for the high level of depressive symptoms; therefore, we conducted several sensitivity analyses using different cutoff points to detect any differences in the findings. Moreover, carotid IMT was not measured at the baseline, therefore it is possible that there are common pathophysiological processes behind the association between depressive symptoms and increased IMT. Finally, the sample was mainly White Caucasian, which limits generalizability of our findings to ethnically more diverse populations. 


\section{Conclusions}

In summary, the findings of this population-based study do not indicate any direct association between depressive symptoms and atherosclerosis in asymptomatic, young adults. This study, however, do not completely question a role of depression in a pathogenesis of CHD, as it may co-vary with some mechanisms leading to CHD but is not causally related to it.

\section{Funding}

This study was supported by the Signe and Ane Gyllenberg Foundation (MH), the Academy of Finland (258711 (LK-J) and 258578 (MH)), and Research Funds of the University of Helsinki (MH). The Young Finns Study has been financially supported by the Academy of Finland: grants 134309 (Eye), 126925, 121584, 124282, 129378 (Salve), 117797 (Gendi), and 41071 (Skidi), the Social Insurance Institution of Finland, Kuopio, Tampere and Turku University Hospital Medical Funds, Juho Vainio Foundation, Sigrid Juselius Foundation, Yrjö Jahnsson Foundation, Paavo Nurmi Foundation, Finnish Foundation of Cardiovascular Research, the Finnish Cultural Foundation, Tampere Tuberculosis Foundation, The Signe and Ane Gyllenberg Foundation (LP-R) and Emil Aaltonen Foundation.

\section{Disclosure of potential conflicts of interests}

The authors declare that they have no conflict of interest.

\section{Research involving Human Participants and/or Animals}

Ethical approval: "All procedures performed in studies involving human participants were in accordance with the ethical standards of the institutional and/or national research committee and with the 1964 Helsinki declaration and its later amendments or comparable ethical standards." 
Depressive symptoms and IMT

\section{Informed consent}

"Informed consent was obtained from all individual participants included in the study; in addition, parents' consent was requested for participants less than 12 years of age in 1980." 


\section{References}

1. Frasure-Smith N, Lesperance F. Depression and cardiac risk: Present status and future directions. Heart. 2010; 96: 173-6.

2. Hemingway H, Marmot M. Evidence based cardiology: Psychosocial factors in the aetiology and prognosis of coronary heart disease. Systematic review of prospective cohort studies. BMJ. 1999; 318: 1460-7.

3. Khan FM, Kulaksizoglu B, Cilingiroglu M. Depression and coronary heart disease. Curr Atheroscler Rep. 2010;12: 105-9.

4. Rugulies R. Depression as a predictor for coronary heart disease. Am J Prev Med. 2002; 23: 51-61.

5. Celano CM, Huffman JC. Depression and cardiac disease. Cardiol Rev. 2011; 19: 13042.

6. Cohen BE, Edmondson D, Kronish IM. State of the art review: Depression, stress, anxiety, and cardiovascular disease. Am J Hypertens. 2015; 28: 1295-302.

7. Lorenz MW, Markus HS, Bots ML, Rosvall M, Sitzer M. Prediction of clinical cardiovascular events with carotid intima-media thickness: A systematic review and meta-analysis. Circulation. 2007; 115: 459-67.

8. Mackinnon AD, Jerrard-Dunne P, Sitzer M, Buehler A, von Kegler S, Markus HS. Rates and determinants of site-specific progression of carotid artery intima-media thickness: The Carotid Atherosclerosis Progression Study. Stroke. 2004; 35: 2150-4.

9. Faramawi MF, Gustat J, Wildman RP, Rice J, Johnson E, Sherwin R. Relation between depressive symptoms and common carotid artery atherosclerosis in American persons $\geq 65$ years of age $\dagger \uparrow$ This report was prepared using a limited-access data set obtained by the National Heart, Lung, and Blood Institute and does not necessaril. Am J Cardiol. 2007; 99: 1610-3. 
10. Tiemeier H, van Dijck W, Hofman A, Witteman JCM, Stijnen T, Breteler MMB. Relationship between atherosclerosis and late-life depression. Arch Gen Psychiatry. 2004; 61: 369-76.

11. Haas DC, Davidson KW, Schwartz DJ, Rieckmann N, Roman MJ, Pickering TG, et al. Depressive symptoms are independently predictive of carotid atherosclerosis. Am J Cardiol. 2005; 95: 547-50.

12. Hamer M, Kivimaki M, Lahiri A, Marmot MG, Steptoe A. Persistent cognitive depressive symptoms are associated with coronary artery calcification. Atherosclerosis. 2010; 210: 209-13.

13. Ohira T, Diez Roux A V., Polak JF, Homma S, Iso H, Wasserman BA. Associations of anger, anxiety, and depressive symptoms with carotid arterial wall thickness. Psychosom Med. 2012; 74: 517-25.

14. Rice SC, Zonderman AB, Metter EJ, Najjar SS, Waldstein SR. Absence of relation between depressive symptoms and carotid intimal medial thickness in the Baltimore Longitudinal Study of Aging. Psychosom Med. 2009; 71: 70-6.

15. Whipple MO, Lewis TT, Sutton-Tyrrell K, Matthews KA, Barinas-Mitchell E, Powell LH, et al. Hopelessness, depressive symptoms, and carotid atherosclerosis in women: The Study of Women's Health Across the Nation (SWAN) Heart Study. Stroke. 2009; 40: $3166-72$.

16. Newson RS, Hek K, Luijendijk HJ, Hofman A, Witteman JCM, Tiemeier H. Atherosclerosis and incident depression in late life. Arch Gen Psychiatry. 2010; 67: 1144-1150.

17. Beutel ME, Wiltink J, Kirschner Y, Sinning C, Espinola-Klein C, Wild PS, et al. History of depression but not current depression is associated with signs of atherosclerosis: Data from the Gutenberg Health Study. Psychol Med. 2014; 44: 919- 
25.

18. Elovainio M, Keltikangas-Järvinen L, Kivimäki M, Pulkki L, Puttonen S, Heponiemi $\mathrm{T}$, et al. Depressive symptoms and carotid artery intima-media thickness in young adults: The Cardiovascular Risk in Young Finns Study. Psychosom Med. 2005; 67: $561-7$.

19. Bus BAA, Marijnissen RM, Holewijn S, Franke B, Purandare N, de Graaf J, et al. Depressive symptom clusters are differentially associated with atherosclerotic disease. Psychol Med. 2011; 41: 1419-28.

20. Pizzi C, Costa GM, Santarella L, Flacco ME, Capasso L, Bert F, et al. Depression symptoms and the progression of carotid intima-media thickness: A 5-year follow-up study. Atherosclerosis. 2014; 233: 530-6.

21. Pizzi C, Manzoli L, Mancini S, Bedetti G, Fontana F, Costa GM. Autonomic nervous system, inflammation and preclinical carotid atherosclerosis in depressed subjects with coronary risk factors. Atherosclerosis. 2010; 212: 292-8.

22. Kabir AA, Srinivasan SR, Sultana A, Chen W, Wei CY, Berenson GS. Association between depression and intima-media thickness of carotid bulb in asymptomatic young adults. Am J Med. 2009; 122: 1151.e1-1151.e8.

23. Jones DJ, Bromberger JT, Sutton-Tyrrell K, Matthews KA. Lifetime history of depression and carotid atherosclerosis in middle-aged women. Arch Gen Psychiatry. 2003; 60: 153-60.

24. Raitakari OT, Juonala M, Ronnemaa T, Keltikangas-Jarvinen L, Rasanen L, Pietikainen M, et al. Cohort profile: The Cardiovascular Risk in Young Finns Study. Int J Epidemiol. 2008; 37: 1220-6.

25. Beck AT, Steer RA. Manual for the revised Beck Depression Inventory. San Antonio, TX: Psychological corporation; 1987. 
26. Katainen S. Temperament and Development: A Longitudinal Study of TemperamentMothering Interaction and the Development of Temperament, Depressive Tendencies and Hostility [disseration]. Helsinki: University of Helsinki; 1999.

27. Rosenström T, Jokela M, Puttonen S, Hintsanen M, Pulkki-Råback L, Viikari JS, et al. Pairwise measures of causal direction in the epidemiology of sleep problems and depression. Gilestro GF, editor. PLoS One. 2012; 7: e50841.

28. Rosenström T, Jokela M, Hintsanen M, Pulkki-Råback L, Hutri-Kähönen N, Keltikangas-Järvinen L. Longitudinal course of depressive symptoms in adulthood: Linear stochastic differential equation modeling. Psychol Med. 2013; 43: 933-44.

29. Raitakari OT, Juonala M, Kähönen M, Taittonen L, Laitinen T, Mäki-Torkko N, et al. Cardiovascular risk factors in childhood and carotid artery intima-media thickness in adulthood. JAMA. 2003; 290: 2277-83.

30. Koskinen J, Kahonen M, Viikari JSA, Taittonen L, Laitinen T, Ronnemaa T, et al. Conventional cardiovascular risk factors and metabolic syndrome in predicting carotid intima-media thickness progression in young adults: The Cardiovascular Risk in Young Finns Study. Circulation. 2009; 120: 229-36.

31. Flu W-J, van Kuijk J-P, Hoeks SE, Kuiper R, Schouten O, Goei D, et al. Intima media thickness of the common carotid artery in vascular surgery patients: A predictor of postoperative cardiovascular events. Am Heart J. 2009; 158: 202-8.

32. Friedewald WT, Levy RI, Fredrickson DS. Estimation of the concentration of lowdensity lipoprotein cholesterol in plasma, without use of the preparative ultracentrifuge. Clin Chem. 1972; 18: 499-502.

33. Royston P, White IR. Multiple imputation by chained equations (MICE): Implementation in Stata. J Stat Softw. 2011; 45: 1-20.

34. Lee Y-H, Shin M-H, Choi J-S, Nam H-S, Jeong S-K, Park K-S, et al. Gender 
differences in the association between depressive symptoms and carotid atherosclerosis among middle-aged and older Koreans: The Namwon Study. J Korean Med Sci. 2014; 29: 1507-13.

35. Everson SA, Kaplan GA, Goldberg DE, Salonen R, Salonen JT. Hopelessness and 4year progression of carotid atherosclerosis : The Kuopio Ischemic Heart Disease Risk Factor Study. Arterioscler Thromb Vasc Biol. 1997; 17: 1490-5.

36. Meijer A, Zuidersma M, de Jonge P. Depression as a non-causal variable risk marker in coronary heart disease. BMC Med. 2013; 11: 130.

37. Kop WJ, Gottdiener JS. The role of immune system parameters in the relationship between depression and coronary artery disease. Psychosom Med. 2005; 67: S37-41.

38. Stetler C, Miller GE. Depression and hypothalamic-pituitary-adrenal activation: A quantitative summary of four decades of research. Psychosom Med. 2011; 73: 114-26.

39. Carney RM, Freedland KE, Veith RC. Depression, the autonomic nervous system, and coronary heart disease. Psychosom Med. 2005; 67: S29-33.

40. Bruce EC, Musselman DL. Depression, alterations in platelet function, and ischemic heart disease. Psychosom Med. 2005; 67: S34-36.

41. Villareal DT, Miller BVI, Banks M, Fontana L, Sinacore DR, Klein S. Effect of lifestyle intervention on metabolic coronary heart disease risk factors in obese older adults. Am J Clin Nutr. 2006; 84: 1317-23.

42. Sutin AR, Terracciano A, Milaneschi Y, An Y, Ferrucci L, Zonderman AB. The trajectory of depressive symptoms across the adult life span. JAMA Psychiatry. 2013; 70: 803-811.

43. Stewart JC, Janicki DL, Muldoon MF, Sutton-Tyrrell K, Kamarck TW. Negative emotions and 3-year progression of subclinical atherosclerosis. Arch Gen Psychiatry. 2007; 64: 225-33. 
44. Bots ML, Hofman A, Grobbee DE. Increased common carotid intima-media thickness: Adaptive response or a reflection of aherosclerosis? Findings from the Rotterdam Study. Stroke. 1997; 28: 2442-7.

45. Folsom AR, Kronmal RA, Detrano RC, O’Leary DH, Bild DE, Bluemke DA, et al. Coronary artery calcification compared with carotid intima-media thickness in the prediction of cardiovascular disease incidence: The Multi-Ethnic Study of Atherosclerosis (MESA). Arch Intern Med. 2008; 168: 1333-1339. 
Table 1. Characteristics of the study participants $(n=996)$

\begin{tabular}{|c|c|c|c|c|c|}
\hline & \multicolumn{2}{|c|}{$\operatorname{Men}(n=352)$} & \multicolumn{2}{|c|}{ Women $(n=644)$} & \multirow[b]{2}{*}{$p$-value } \\
\hline & Mean (SD) & Range & Mean (SD) & Range & \\
\hline Age in 1980 , years & $10.2(4.98)$ & $3-18$ & $10.8(5.04)$ & $3-18$ & 0.106 \\
\hline \multicolumn{6}{|l|}{ Childhood risk factors } \\
\hline LDL-cholesterol, mmol/1 & $3.3(0.71)$ & $1.09-6$ & $3.4(0.76)$ & $1.62-7.55$ & 0.079 \\
\hline Body mass index, $\mathrm{kg} / \mathrm{m}^{2}$ & $17.6(2.95)$ & $9.2-36.02$ & $17.8(2.83)$ & $12.79-28.33$ & 0.286 \\
\hline Systolic blood pressure, $\mathrm{mm} \mathrm{Hg}$ & $112.9(12.51)$ & $78-164.67$ & $111.8(11.2)$ & $68-140.67$ & 0.175 \\
\hline \multicolumn{6}{|l|}{ Adulthood risk factors } \\
\hline LDL-cholesterol, mmol/1 & $3.3(0.83)$ & $0.85-6.56$ & $2.9(0.72)$ & $0.75-5.47$ & 0.001 \\
\hline Body mass index, $\mathrm{kg} / \mathrm{m}^{2}$ & $26.3(3.95)$ & $17.54-45.89$ & $25.2(4.58)$ & $16.56-47.33$ & 0.001 \\
\hline Systolic blood pressure, $\mathrm{mm} \mathrm{Hg}$ & $125.2(12.21)$ & $97-168.67$ & $116.4(13.28)$ & $88-162.67$ & 0.001 \\
\hline Daily smokers (\%) & $16.8 \%$ & & $13.98 \%$ & & 0.239 \\
\hline Carotid IMT, mm & $0.63(0.11)$ & $0.4-1.08$ & $0.61(0.09)$ & $0.41-1.04$ & 0.001 \\
\hline IMT progression, mm & $0.05(0.09)$ & $-0.24-0.42$ & $0.04(0.08)$ & $-0.20-0.29$ & 0.069 \\
\hline Accumulative depression index & $5.94(1.57)$ & $3.10-11.29$ & $6.42(1.61)$ & $3.24-11.46$ & 0.001 \\
\hline
\end{tabular}

Note. LDL-cholesterol = low-density lipoprotein cholesterol, IMT = intima-media thickness 
Table 2. Correlation coefficients between childhood and adulthood risk factors and accumulative depression index

\section{Accumulative depression index}

\begin{tabular}{|c|c|c|c|}
\hline & \multirow[b]{2}{*}{$\begin{array}{l}\text { Complete cases } \\
\qquad(n=996)\end{array}$} & \multirow[b]{2}{*}{$\begin{array}{c}\text { Men } \\
(n=352)\end{array}$} & \multirow[b]{2}{*}{$\begin{array}{l}\text { Women } \\
(n=644)\end{array}$} \\
\hline & & & \\
\hline Age in 1980 , years & -0.02 & -0.00 & -0.04 \\
\hline \multicolumn{4}{|l|}{ Childhood risk factors } \\
\hline LDL-cholesterol, mmol/1 & -0.1 & -0.00 & -0.03 \\
\hline Body mass index, $\mathrm{kg} / \mathrm{m}^{2}$ & 0.00 & 0.04 & -0.03 \\
\hline Systolic blood pressure, $\mathrm{mm} \mathrm{Hg}$ & -0.04 & -0.04 & -0.04 \\
\hline \multicolumn{4}{|l|}{ Adulthood risk factors } \\
\hline LDL-cholesterol, mmol/1 & -0.04 & -0.2 & -0.01 \\
\hline Body mass index, $\mathrm{kg} / \mathrm{m}^{2}$ & $0.10 * *$ & $0.17 * *$ & $0.10 *$ \\
\hline Systolic blood pressure, $\mathrm{mm} \mathrm{Hg}$ & -0.02 & 0.04 & 0.02 \\
\hline Daily smokers (\%) & $0.07 * *$ & 0.05 & $0.09 *$ \\
\hline Carotid IMT, mm & -0.01 & 0.01 & 0.01 \\
\hline IMT progression, $\mathrm{mm}$ & 0.05 & 0.05 & 0.06 \\
\hline
\end{tabular}

Note. ${ }^{* * *} p<.001, * * p<.01, * p<.05$ 
Table 3. Unstandardized regression coefficients for accumulative depression index predicting carotid IMT and IMT progression, men and women combined

\begin{tabular}{|c|c|c|c|c|}
\hline \multirow[t]{2}{*}{ Complete cases } & \multicolumn{2}{|c|}{ Carotid IMT } & \multicolumn{2}{|c|}{ Carotid IMT progression $\dagger$} \\
\hline & B (SE) & $95 \% \mathrm{CI}$ & B (SE) & $95 \% \mathrm{CI}$ \\
\hline \multicolumn{5}{|l|}{ Model 1} \\
\hline Age, years & $0.007(0.001) * * *$ & $0.006,0.008$ & $0.004(0.001)^{* * *}$ & $0.003,0.005$ \\
\hline Male sex & $0.028(0.006) * * *$ & $0.016,0.039$ & $0.002(0.005) * * *$ & $0.009,0.029$ \\
\hline Accumulative depression index & $0.001(0.002)$ & $-0.002,0.005$ & $0.002(0.002)$ & $-0.001,0.005$ \\
\hline \multicolumn{5}{|l|}{ Model 2} \\
\hline Age, years & $0.005(0.001) * * *$ & $0.003,0.007$ & $0.003(0.001)^{* * *}$ & $0.001,0.004$ \\
\hline Male sex & $0.017(0.006)^{* *}$ & $0.005,0.029$ & $0.014(0.005)^{*}$ & $0.003,0.025$ \\
\hline \multicolumn{5}{|l|}{ Childhood risk factors } \\
\hline LDL-cholesterol, mmol/1 & $0.001(0.004)$ & $-0.008,0.009$ & $0.001(0.004)$ & $-0.007,0.009$ \\
\hline Body mass index, $\mathrm{kg} / \mathrm{m}^{\wedge} 2$ & $0.002(0.001)$ & $-0.001,0.005$ & $0.001(0.001)$ & $-0.001,0.004$ \\
\hline Systolic blood pressure, $\mathrm{mm} \mathrm{Hg}$ & $0.001(0.000)^{* *}$ & $0.000,0.001$ & $0.001(0.000)^{*}$ & $0.000,0.001$ \\
\hline
\end{tabular}


Depressive symptoms and IMT

\begin{tabular}{lllll} 
LDL-cholesterol, mmol/1 & $0.003(0.004)$ & $-0.006,0.011$ & $0.005(0.004)$ & $-0.002,0.013$ \\
Body mass index, $\mathrm{kg} / \mathrm{m}^{\wedge} 2$ & $\mathbf{0 . 0 0 4}(\mathbf{0 . 0 0 1}) * * *$ & $\mathbf{0 . 0 0 2}, \mathbf{0 . 0 0 5}$ & $\mathbf{0 . 0 0 2}(\mathbf{0 . 0 0 1}) * * *$ & $\mathbf{0 . 0 0 1 , 0 . 0 0 4}$ \\
Systolic blood pressure, $\mathrm{mm} \mathrm{Hg}$ & $0.000(0.000)$ & $-0.000,0.001$ & $0.000(0.000)$ & $-0.000,0.000$ \\
Daily smoking & $0.005(0.007)$ & $-0.010,0.020$ & $-0.001(0.007)$ & $-0.014,0.013$ \\
Accumulative depression index & $-0.000(0.002)$ & $-0.003,0.003$ & $0.002(0.002)$ & $-0.001,0.005$ \\
\hline
\end{tabular}

Note. $* * * p<.001, * * p<.01, * p<.05$.

$†$ Baseline carotid IMT (measured in 2001) was included into Model 1 and Model 2 as a control variable. 